\title{
Buffering Effect of Spousal Support on Stress Levels in Mothers of Children with a Diagnosis of Autism Spectrum Disorder in Kerala, India
}

\author{
Prinu Jose ${ }^{1}$ Soumya Sundaram ${ }^{2,3}$ Ravi Prasad Varma ${ }^{1,3, \oplus}$ \\ ${ }^{1}$ Achutha Menon Center for Health Science Studies, Sree Chitra \\ Tirunal Institute for Medical Sciences and Technology, Trivandrum, \\ Kerala, India \\ ${ }^{2}$ Department of Neurology, Sree Chitra Tirunal Institute for Medical \\ Sciences and Technology, Trivandrum, Kerala, India \\ ${ }^{3}$ Comprehensive Care Centre for Neurodevelopmental Disorders \\ (CCCND), Sree Chitra Tirunal Institute for Medical Sciences and \\ Technology, Trivandrum, Kerala, India
}

Address for correspondence Ravi Prasad Varma, MD, Achutha Menon Center for Health Science Studies, Sree Chitra Tirunal Institute for Medical Sciences and Technology, Trivandrum 695011, Kerala, India (e-mail: rpvarma@sctimst.ac.in).

\begin{abstract}
Keywords

- autism spectrum disorder

- psychological elements

- mothers

- spouses

- social support

Objectives Bringing up a child with the diagnosis of autism spectrum disorder (ASD) can be highly stressful. This study aimed to assess perceived stress, level of spousal support, emotion-focused coping styles, and other potentially associated factors among mothers accompanying children diagnosed with ASD for care from selected institutions in Kerala, India.

Materials and Methods Consenting parents accompanying children to therapeutic programs in selected institutions were administered a semi structured interview schedule incorporating questions of the vernacular version of the Perceived Stress Scale (PSS-10), emotion-based coping strategies, spousal support in care of the child diagnosed with ASD, and possible-associated factors. Since internal consistency of stress and coping questionnaires were low, principal component analysis was used to extract composite variables with reasonable psychometric characteristics for stress and coping.

Statistical Analysis Ordinal logistic regression was performed with a three-level stress category as the outcome variable.

Results High stress was significantly associated with low spousal support (adjusted odds ratio or AOR: 2.80; 95\% confidence intervals or Cl 1.28-6.11), having a completely dependent child (AOR 4.24 [95\% Cl 1.92-9.38]), and low acceptance levels (AOR 2.60 [95\% Cl 1.14-5.89]). Unlike mothers with high spousal support, mothers with low spousal support were likely to have difficulty in interacting with others ( $p=$ $0.02)$ and a low level of acceptance $(p=0.05)$.

Conclusion Spousal support is important to preserve psychological health in mothers of children diagnosed with ASD. Mothers with low spousal support may need interventions that help increase acceptance levels or decrease avoidant behavior.
\end{abstract}

published online June 16, 2021
DOI https://doi.org/

$10.1055 / \mathrm{s}-0041-1727559$ ISSN 0976-3147
(C) 2021. Association for Helping Neurosurgical Sick People.

This is an open access article published by Thieme under the terms of the Creative Commons Attribution-NonDerivative-NonCommercial-License, permitting copying and reproduction so long as the original work is given appropriate credit. Contents may not be used for commercial purposes, or adapted, remixed, transformed or built upon. (https://creativecommons.org/licenses/by-nc-nd/4.0/). Thieme Medical and Scientific Publishers Pvt. Ltd. A-12, 2nd Floor, Sector 2, Noida-201301 UP, India 


\section{Introduction}

Stress in parents of children diagnosed with autism spectrum disorders (ASDs) may be precipitated and sustained due to the symptoms of ASD, lengthy diagnostic processes, the interventions that require intensive parental participation, and uncertain prognosis. ${ }^{1}$ Problems related to employment, finances, and social relationships may add new stressors on a regular basis for such parents. Unfavorable allostasis, the persistent stimulation of biological systems related to the response to stress, will cause negative psychological and physical outcomes. ${ }^{2}$ Social and material resources may have a role in the progression to a stage of physical or psychological dysfunction. Unfavorable health outcomes were found to be higher in mothers from poor socio-economic situations, ${ }^{3}$ and economic hardship was considered as a strong predictor of parental wellbeing. ${ }^{4}$ This indicates that poor parents may end up with a higher allostatic load. Successful adaptation and continued functioning at an optimal level in the face of high stress needs good resilience. Psychological, social, and environmental factors that help increasing the level of resilience in persons may often be amenable to intervention. ${ }^{5}$ As expounded by Lindström and Eriksson, Antonovsky had identified several general resistance resources such as genetic, constitutional, material, psychological, cognitive, coping-based, social support based and cultural or religious stability that persons may use or re-use to adapt to stressors. ${ }^{6}$ Better social connectedness has been found to help alleviate the adverse effects of chronic stress. ${ }^{7}$ Social support constitutes the tangible or intangible support outside the inherent psychological resources that an individual receives from another individual or group. Support from other people may include spousal support or support from a "significant other" and support from family or friends. Spousal support is a reflection of marital quality and good marital quality of mothers of children diagnosed with ASD have been shown to be concurrently associated with better adjustment, parenting efficacy, and wellbeing. ${ }^{8}$ High spousal support has also been shown to be associated with better physical and mental health functioning in mothers of sick children. ${ }^{9}$ Support that is expressed is very important in determining parental quality. Some studies have suggested that fathers may involve less with the care of disabled children than neurotypical children. ${ }^{10}$ This is particularly important for mothers of children diagnosed with ASD in low- and middle-income countries like India where child rearing is predominantly in the mother's domain. In a cultural setting marked by heteronormative patriarchy, the main source of support for a woman is her husband or immediate family members. The role of social support beyond this immediate circle may be limited, despite being important. ${ }^{11}$ There is a need to study maternal emotional responses and their relationship with paternal involvement in care of children diagnosed with ASD.

An institution-based cross-sectional study was done in Kerala state of India to assess stress levels and coping strategies among parents of children diagnosed with ASD. The current manuscript focuses on the mother who participated, and explores the level of spousal support in its relationship to maternal stress levels.

\section{Materials and Methods}

\section{Design and Setting}

An institution-based cross-sectional study was done among parents accompanying a child diagnosed with ASD to three specialty clinics, one intermediary facility, and one basic facility in Trivandrum district in Kerala state, India. Kerala state is known for good health indicators including child survival and very good access to biomedical care. But Kerala does not have the same saturation of multidisciplinary care that is characteristic of high-income countries. ${ }^{12}$

\section{Participants}

The accompanying parent of a child up to 18 years of age with ASD visiting each institution during the study period (June 2018 to August 2018) was approached for participation in the study. Parents of children with a recent (within 1 month) diagnosis of ASD were excluded. The study could recruit 99 mothers but only 11 fathers. As the current paper focused on mothers of children diagnosed with ASD, we excluded fathers from further analysis.

\section{Data Collection}

A peer reviewed semi-structured interview schedule was used to collect data. Prospective parents were first informed about the study by the primary therapist at the institution they were visiting and referred to the investigator if they were willing to participate. Study description, consenting, and interviews were conducted by the same investigator for the sake of uniformity.

\section{Variables}

The interview schedule comprised of questions on socio-demographic characteristics including age, socioeconomic status based on state allotted categorization as below-poverty line or not, basic aspects of the diagnosis and treatment of the child, and potential factors associated with stress and coping strategies including sources of support parents received for various responsibilities. We incorporated 10 items based on the Cohen's and Williamson's Perceived Stress Scale (PSS-10), ${ }^{13}$ and 16 items covering four domains of emotion-based coping strategies, namely positive reinterpretation, acceptance, religiosity, and emotional support received. ${ }^{14}$ We prioritized on the emotion-based coping strategies in this study as we were focusing on the emotional experiences of the parents rather than the actions taken.

\section{Analysis}

Data entry, cleaning, and quantitative analysis were done in IBM Statistical Package for the Social Sciences (SPSS) version 25. Spousal support was assessed based on the reported role of the spouse and level of engagement in the care of autistic child and accompanying the child for therapeutic sessions. Spouses were considered supportive if mothers mentioned them as having equal or more responsibility in any of the aforementioned roles. Scale reliability of the stress and coping scales were assessed using Cronbach's $\alpha$. As raw scales had very low $\alpha$ values, underlying factors related to stress and coping were assessed to derive stress 
and coping scores. Principal component analysis with varimax rotation was used to reduce the number of variables and get a combination of factors with better internal consistency. The remaining items were added up to get summative scores. A receiver operator characteristic (ROC) curve was plotted to look at the ability of the computed stress score to identify mothers who need screening for anxiety disorder. Mothers were categorized as needing screening for anxiety disorder if they reported avoiding social gatherings "all the time" and labeled their anxiety level as "much higher." With respect to coping, only the factors that were extracted with eigenvalue over one were considered for developing summative domain scores. These domain scales were categorized as low or high based on the median score for the respective domain.

Summative stress scores were categorized into three based on terciles to obtain the outcome variable-low, intermediate, or high stress level. Chi-square tests (or Fisher exact test) were used to compare the proportions of mothers across different stress categories for each independent variable. Those variables that had a $p$-value less than 0.01 were carried forward to ordinal logistic regression analysis with a constrained cumulative logit model (proportional odds model). Variables significant in one-to-one regression analysis with the outcome variable were incorporated to a multiple ordinal regression model. Assumptions of proportional odds (Chi-square test for model fit), goodness of fit, and parallelism (Chi-square test for parallel lines) were checked and odds ratios with $95 \%$ confidence intervals were estimated. Only the main effects were computed as the sample numbers were inadequate to explore possible interactions with regression analysis. However, we report stratified proportions to suggest possible interactions between spousal support, stress levels, and other variables.

\section{Ethical Considerations}

Consenting processes were in line with the relevant regulations of the Indian Council for Medical Research. ${ }^{15}$ Participants were assured privacy, confidentiality, and noneffect on availed services for the child/ parent whether they chose to participate or not. The study protocol received clearance from the Institutional Ethics Committee (IEC) of host institution (the Sree Chitra Tirunal Institute for Medical Sciences and Technology, Trivandrum.). The IEC is registered under the relevant legislation in India. ${ }^{16}$

\section{Results}

All parents who were approached during the study period consented to participate. The characteristics of the participating mothers are listed in - Table 1. About two-thirds of the mothers had educational levels above secondary school and were from nonpoor households. A significant minority of the mothers were found to be at risk of having possible anxiety disorder, needing further evaluation. Twelve mothers were in consanguineous marriages and two had another child diagnosed as having a developmental disorder. Fifty mothers had two children and 43 had only one child. All 20 mothers who were in regular employment reported having to decrease working hours due to the diagnosis received by the child. Only 18 mothers had received some form of financial assistance to assist with care of the child diagnosed with ASD.

\section{Stress Levels}

The scale based on the raw items of the PSS Score had a Cronbach's $\alpha$ of 0.323 . The item on anger (item 9) had a very high ceiling effect with almost one-third of the mothers choosing the highest possible response. The factor structure that emerged in dimension reduction analysis comprised of four items (items 1,2,3, and 10). These items, shown in the upper factor structure in - Fig. 1, had good covariance. Sampling adequacy criteria for items and correlation matrix were met. Extracted communalities were 0.5 or higher and one component with eigenvalue 2.1 was extracted. The four items together had a Cronbach's $\alpha$ of 0.69 . When added together, they gave a variable ranging with values from one to 16 , with a mean of 10.0 (standard deviation or SD 3.4). Based on tercile values of nine and 12, mothers were divided into three groups-31 with low stress, 34 with medium stress, and 34 with high stress.

Table 1 Characteristics of participating mothers

\begin{tabular}{|c|c|c|}
\hline Variable & Categories & $n=99$ \\
\hline \multirow[t]{2}{*}{ Age group } & $18-34$ & 68 \\
\hline & 35 and above & 31 \\
\hline \multirow[t]{2}{*}{ Educational status } & $\begin{array}{l}\text { Up to secondary school } \\
\text { (approximately } 10 \mathrm{y} \text { ) }\end{array}$ & 20 \\
\hline & $\begin{array}{l}\text { Above secondary } \\
\text { school }\end{array}$ & 79 \\
\hline \multirow[t]{2}{*}{ Socioeconomic status ${ }^{a}$} & Poor & 35 \\
\hline & Nonpoor & 64 \\
\hline \multirow[t]{2}{*}{ Employment status } & Working & 20 \\
\hline & Quit job/Not employed & 79 \\
\hline \multirow{2}{*}{$\begin{array}{l}\text { Self-reported difficulty in } \\
\text { interactions with others }\end{array}$} & No & 53 \\
\hline & Yes & 46 \\
\hline \multirow{2}{*}{$\begin{array}{l}\text { Needs screening for anxiety } \\
\text { disorder }\end{array}$} & No & 79 \\
\hline & Yes & 20 \\
\hline \multirow{2}{*}{$\begin{array}{l}\text { Any counseling or therapy } \\
\text { received }\end{array}$} & No & 81 \\
\hline & Yes & 18 \\
\hline \multirow{2}{*}{$\begin{array}{l}\text { Perceived spousal support in } \\
\text { ASD management }\end{array}$} & High & 47 \\
\hline & Low & 52 \\
\hline \multirow{4}{*}{$\begin{array}{l}\text { Age of the child diagnosed } \\
\text { with ASD }\end{array}$} & $1-3 y$ & 43 \\
\hline & $4-6 y$ & 33 \\
\hline & $7-11 y$ & 10 \\
\hline & $12-18 y$ & 13 \\
\hline \multirow[t]{2}{*}{ Sex of the child } & Male & 78 \\
\hline & Female & 21 \\
\hline \multirow{2}{*}{$\begin{array}{l}\text { Parent perceived level of } \\
\text { dependence of child }\end{array}$} & Partial & 50 \\
\hline & Complete & 49 \\
\hline \multirow{2}{*}{$\begin{array}{l}\text { Mixed disabilities diagnosed } \\
\text { in the child }\end{array}$} & No & 72 \\
\hline & Yes & 27 \\
\hline
\end{tabular}

Abbreviation: ASD, autism spectrum disorder.

aBased on state determined household economic benchmarks. 

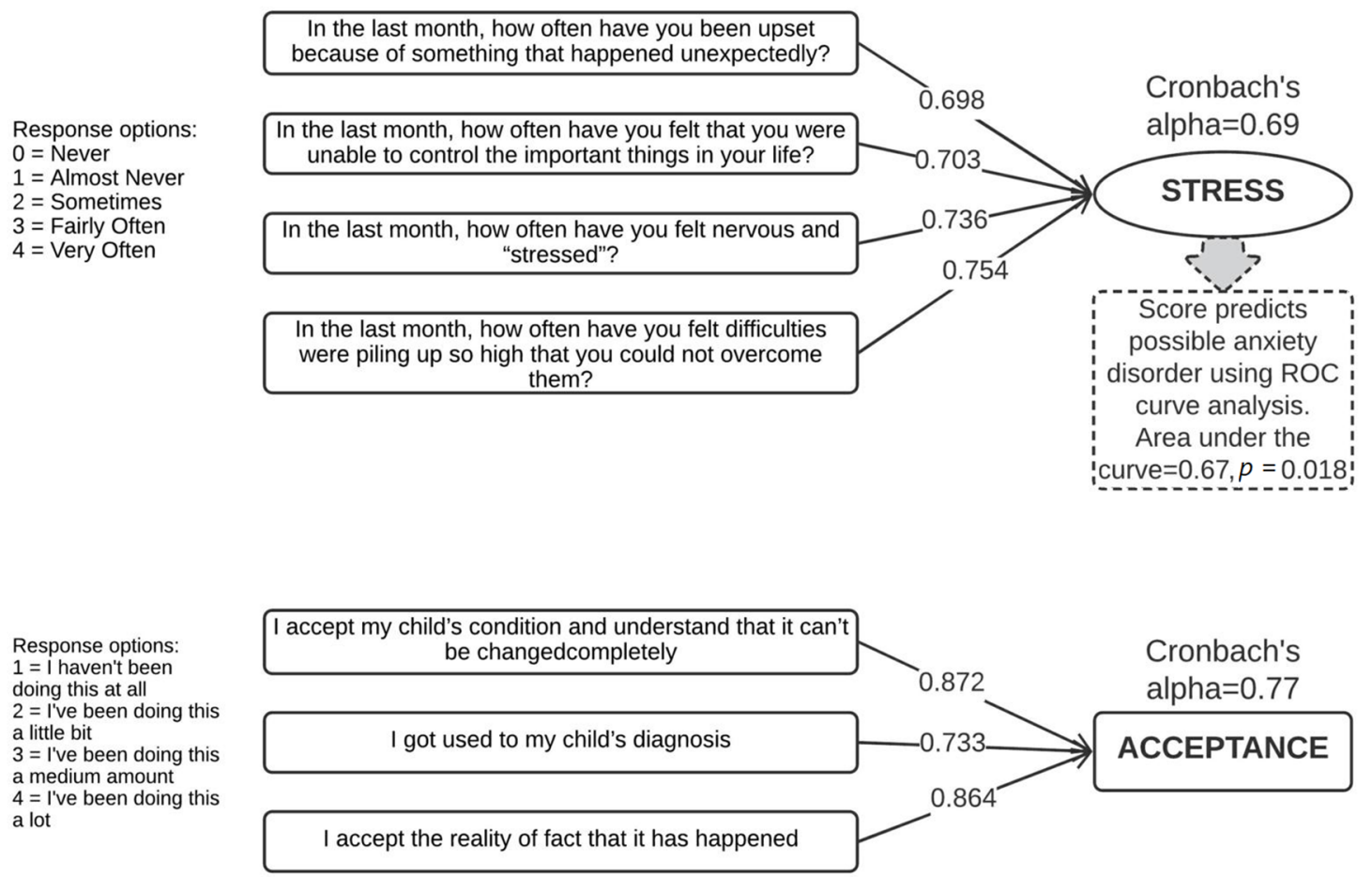

Fig. 1 Items contributing to computation of composite stress score and score for acceptance level; results of principal component analysis and ROC curve analysis. ROC, receiver operator characteristic.

\section{Coping}

Only two factors could be extracted from the four potential domains of coping assessed. The first one had an eigenvalue of 2.6 and corresponded to the domain religiosity and all four items were retained. The second one had an eigenvalue of 2.1 and corresponded to the domain acceptance. Only three items, as shown in lower factor structure in - Fig. 1, corresponding to acceptance levels were retained. Two additive scores with the upper tercile 13.6 for religiosity and 11 for acceptance were obtained. Two new variables were derived to indicate a high level of religiosity and coping based on the mothers who scored more than the upper tercile value.

\section{Spousal Support}

Paternal support was predominant in accompanying the child for therapeutic intervention sessions as compared with care of the affected child at home, with 44 fathers playing an equal or larger role than the mothers in accompanying the child to treatment sessions while only 12 fathers took up the role of the main caregiver of the child at home. Only nine fathers had a dominant role in both aspects of care of the child diagnosed with ASD by being equally or more responsible than the mother for care of the child at home as well as accompanying the child for therapeutic intervention sessions. Three mothers reported absolutely no support of this form-one was divorced and one separated while the third was still living within her marriage.

\section{Increasing Stress Levels and Spousal Support}

Mothers were likely to fall into a higher category of stress if spousal support was low $(p=0.05)$, as shown in - Table 2 . Additionally, they were likely to have moderate or high stress if they were from poor households, had a child who was completely dependent on them due to the severity of symptoms $(p<0.05)$, had a child diagnosed with mixed disabilities $(p=$ 0.08 ), had difficulty in interacting with other persons around her or had possible anxiety disorder $(p=0.06)$. Mothers who were deemed as having a high level of acceptance were less likely to be in the moderate or the high stress group $(p=0.05)$.

The results of ordinal logistic regression are shown in - Table 3. The first model (Model 1) included all variables significant in bivariate analysis, but violated several assumptions of ordinal regression. There were many cells with zero values. The goodness-of-fit Chi-square values suggest inadequacy of the sample size. The second model (Model 2) met these assumptions, but we could adjust the effect of spousal support only for two other variables-level of dependence of the child and level of acceptance by the mother. In both the models, low spousal support was independently associated with mothers falling in the moderate or high stress category as opposed to the low stress category. The risk was almost three times (adjusted odds ratio [AOR] 2.80; [95\% confidence intervals or CI 1.28-6.11]). Having a completely dependent child probably continued to have a very strong gradient of risk, and low acceptance remained significant too. 
Table 2 Stress levels in mothers according to potential-associated factors (Chi-square or Fisher Exact test $p<0.10$ )

\begin{tabular}{|c|c|c|c|c|}
\hline \multirow[t]{2}{*}{ Independent variables } & \multicolumn{3}{|l|}{ Stress levels } & \multirow[t]{2}{*}{$p$-Value } \\
\hline & Low $n=31$ & Medium $n=34$ & High $n=34$ & \\
\hline \multicolumn{5}{|c|}{ Spousal support in ASD management } \\
\hline High & $20(64.5 \%)$ & $15(44.1 \%)$ & $12(35.3 \%)$ & \multirow[t]{2}{*}{0.055} \\
\hline Low & $11(35.5 \%)$ & $19(55.9 \%)$ & $22(64.7 \%)$ & \\
\hline \multicolumn{5}{|l|}{ Socioeconomic status } \\
\hline Nonpoor & $25(80.6 \%)$ & $20(58.8 \%)$ & $19(55.9 \%)$ & \multirow[t]{2}{*}{0.077} \\
\hline Poor & $6(19.4 \%)$ & $14(41.2 \%)$ & $15(44.1 \%)$ & \\
\hline \multicolumn{5}{|c|}{ Parent perceived level of dependence of child } \\
\hline Partial & $24(77.4 \%)$ & $15(44.1 \%)$ & $11(32.4 \%)$ & \multirow[t]{2}{*}{0.001} \\
\hline Complete & $7(22.6 \%)$ & 19 (55.9\%) & $23(67.6 \%)$ & \\
\hline \multicolumn{5}{|c|}{ Mixed disabilities diagnosed in the child } \\
\hline No & $25(80.6 \%)$ & $27(79.4 \%)$ & $20(58.8 \%)$ & \multirow[t]{2}{*}{0.080} \\
\hline Yes & $6(19.4 \%)$ & $7(20.6 \%)$ & $14(41.2 \%)$ & \\
\hline \multicolumn{5}{|c|}{ Difficulty in interacting with others } \\
\hline No & $22(71.0 \%)$ & $16(47.1 \%)$ & $15(44.1 \%)$ & \multirow[t]{2}{*}{0.062} \\
\hline Yes & $9(29.0 \%)$ & 18 (52.9\%) & $19(55.9 \%)$ & \\
\hline \multicolumn{5}{|l|}{ Acceptance level } \\
\hline Low & $15(48.4 \%)$ & $25(75.3 \%)$ & $25(75.3 \%)$ & \multirow[t]{2}{*}{0.05} \\
\hline High & $16(51.6 \%)$ & $9(26.5 \%)$ & $9(26.5 \%)$ & \\
\hline
\end{tabular}

Abbreviation: ASD, autism spectrum disorder.

Note: Proportions indicate column percentages.

Table 3 Results of ordinal logistic regression with outcome stress level in mothers as three ordered categories

\begin{tabular}{|c|c|c|c|c|c|c|}
\hline \multirow[t]{2}{*}{ Factor } & \multicolumn{3}{|l|}{ Model 1} & \multicolumn{3}{|l|}{ Model 2} \\
\hline & Estimate & $p$-Value & $\begin{array}{l}\text { Odds ratio } \\
95 \% \mathrm{Cl}\end{array}$ & Estimate & $p$-Value & $\begin{array}{l}\text { Odds ratio } \\
95 \% \mathrm{Cl}\end{array}$ \\
\hline Intercept 1 & 0.713 & 0.001 & & 0.974 & 0.895 & \\
\hline Intercept 2 & 2.618 & $<0.001$ & & 2.728 & $<0.001$ & \\
\hline \multicolumn{7}{|c|}{ Spousal support in ASD management (High as reference category) } \\
\hline Low & 1.089 & 0.009 & $\begin{array}{l}2.97 \\
1.32-6.71\end{array}$ & 1.029 & 0.01 & $\begin{array}{l}2.80 \\
1.28-6.11\end{array}$ \\
\hline \multicolumn{7}{|c|}{ Socioeconomic status (Nonpoor as reference category) } \\
\hline Poor & 0.133 & 0.765 & $\begin{array}{l}1.14 \\
0.48-2.74\end{array}$ & - & - & - \\
\hline \multicolumn{7}{|c|}{ Level of dependence of child (Partial as reference category) } \\
\hline Complete & 1.551 & $<0.001$ & $\begin{array}{l}4.72 \\
2.01-11.04\end{array}$ & 1.445 & $<0.001$ & $\begin{array}{l}4.24 \\
1.92-9.38\end{array}$ \\
\hline \multicolumn{7}{|c|}{ Mixed disabilities diagnosed in the child (No as reference category) } \\
\hline Yes & 1.029 & 0.041 & $\begin{array}{l}2.80 \\
1.04-7.50\end{array}$ & - & - & - \\
\hline \multicolumn{7}{|c|}{ Difficulty in interacting with others (No as reference category) } \\
\hline Yes & 0.934 & 0.024 & $\begin{array}{l}2.55 \\
1.13-5.73\end{array}$ & - & - & - \\
\hline \multicolumn{7}{|c|}{ Acceptance level (High as reference category) } \\
\hline Low & 1.08 & 0.017 & $\begin{array}{l}2.95 \\
1.21-7.15\end{array}$ & 0.954 & 0.022 & $\begin{array}{l}2.60 \\
1.14-5.89\end{array}$ \\
\hline \multirow{6}{*}{$\begin{array}{l}\text { Model } \\
\text { characteristics }\end{array}$} & \multicolumn{3}{|c|}{68 cells with zero frequencies } & \multicolumn{3}{|c|}{ No cells with zero frequencies } \\
\hline & \multicolumn{3}{|c|}{ Model fitting, $p<0.001$} & \multicolumn{3}{|c|}{ Model fitting, $p<0.001$} \\
\hline & \multicolumn{3}{|c|}{ Goodness of fit, Pearson $=78.8 ; p=0.580$} & \multicolumn{3}{|c|}{ Goodness of fit, Pearson $=9.7 ; p=0.557$} \\
\hline & \multicolumn{3}{|c|}{ Goodness of fit, deviance $=89.1 ; p=0.278$} & \multicolumn{3}{|c|}{ Goodness of fit, deviance $=9.9 ; p=0.544$} \\
\hline & \multicolumn{3}{|c|}{ Parallel lines test, $p=0.185$} & \multicolumn{3}{|c|}{ Parallel lines test, $p=0.269$} \\
\hline & \multicolumn{3}{|c|}{ Pseudo $r$-square (McFadden) $=0.165$} & \multicolumn{3}{|c|}{ Pseudo $r$-square (McFadden) $=0.113$} \\
\hline
\end{tabular}


Table 4 Comparisons of selected risk factors with increasing stress levels stratified according to the level of perceived spousal support

\begin{tabular}{|c|c|c|c|c|c|}
\hline \multirow[t]{2}{*}{ Variable } & & \multicolumn{3}{|l|}{ Stress level } & \multirow[t]{2}{*}{$p$-Value } \\
\hline & & Low & Medium & High & \\
\hline \multicolumn{6}{|l|}{ High spousal support } \\
\hline \multirow[t]{2}{*}{ Socioeconomic status } & Nonpoor & $15(75.0 \%)$ & $12(80.0 \%)$ & $5(41.7 \%)$ & \multirow[t]{2}{*}{0.072} \\
\hline & Poor & $5(25.0 \%)$ & $3(20.0 \%)$ & $7(58.3 \%)$ & \\
\hline \multirow[t]{2}{*}{ Level of dependence of child } & Partial & $16(80.0 \%)$ & $6(40.0 \%)$ & $2(16.7 \%)$ & \multirow[t]{2}{*}{0.001} \\
\hline & Complete & $4(20.0 \%)$ & $9(60.0 \%)$ & $10(83.3 \%)$ & \\
\hline \multirow{2}{*}{$\begin{array}{l}\text { Mixed disabilities diagnosed in the } \\
\text { child }\end{array}$} & No & $17(85.0 \%)$ & $14(93.3 \%)$ & $5(41.7 \%)$ & \multirow[t]{2}{*}{0.004} \\
\hline & Yes & $3(15.0 \%)$ & $1(6.7 \%)$ & 7 (58.3\%) & \\
\hline \multirow[t]{2}{*}{ Difficulty in interacting with others } & No & $12(60.0 \%)$ & $5(33.3 \%)$ & $6(50.0 \%)$ & \multirow[t]{2}{*}{0.294} \\
\hline & Yes & $8(40.0 \%)$ & $10(66.7 \%)$ & $6(50.0 \%)$ & \\
\hline \multirow[t]{2}{*}{ Level of acceptance } & High & $8(40.0 \%)$ & $3(20.0 \%)$ & $4(33.3 \%)$ & \multirow[t]{2}{*}{0.451} \\
\hline & Low & $12(60.0 \%)$ & $12(80.0 \%)$ & $8(66.7 \%)$ & \\
\hline \multicolumn{6}{|l|}{ Low spousal support } \\
\hline \multirow[t]{2}{*}{ Socioeconomic status } & Nonpoor & $10(90.9 \%)$ & 8 (42.1\%) & $14(63.6 \%)$ & \multirow[t]{2}{*}{$0.029^{a}$} \\
\hline & Poor & $1(9.1 \%)$ & $11(57.9 \%)$ & $8(36.4 \%)$ & \\
\hline \multirow[t]{2}{*}{ Level of dependence of child } & Partial & $8(72.7 \%)$ & 9 (47.4\%) & 9 (40.9\%) & \multirow[t]{2}{*}{0.217} \\
\hline & Complete & $3(27.3 \%)$ & $10(52.6 \%)$ & $13(59.1 \%)$ & \\
\hline \multirow{2}{*}{$\begin{array}{l}\text { Mixed disabilities diagnosed in the } \\
\text { child }\end{array}$} & No & $8(72.7 \%)$ & $13(68.4 \%)$ & $15(68.2 \%)$ & \multirow[t]{2}{*}{1.00} \\
\hline & Yes & $3(27.3 \%)$ & $6(31.6 \%)$ & $7(31.8 \%)$ & \\
\hline \multirow[t]{2}{*}{ Difficulty in interacting with others } & No & $10(90.9 \%)$ & $11(57.9 \%)$ & 9 (40.9\%) & \multirow[t]{2}{*}{0.023} \\
\hline & Yes & $1(9.1 \%)$ & $8(42.1 \%)$ & $13(59.1 \%)$ & \\
\hline \multirow[t]{2}{*}{ Level of acceptance } & High & $8(72.7 \%)$ & $6(31.6 \%)$ & $5(22.7 \%)$ & \multirow[t]{2}{*}{$0.054^{a}$} \\
\hline & Low & $3(27.3 \%)$ & $13(68.4 \%)$ & $17(77.3 \%)$ & \\
\hline
\end{tabular}

${ }^{a} p$-Value from Fisher exact test.

Possible two-way and three-way interactions were explored with the variables in model 2 . However, no significant interactions were obtained. Only the model with no interactions is reported. However, some interaction results suggested possibility to generate some hypotheses. For instance, level of dependence and spousal support had a $p$-value of 0.07 . We explored such possibilities by stratifying the mothers into those with low spousal support and with high spousal support.

- Table 4 depicts the comparison of risk factors for high stress stratified based on the level of spousal support. When spousal support was high, the stress levels in mothers seem to be determined by severity of the child's condition. Mothers with higher degrees of stress were likely to have a fully dependent child or a child diagnosed with a mixed disorder. If spousal support was low, then there was less variation in maternal stress levels with respect to the child's condition. In such mothers, low levels of stress were associated with her level of acceptance and ability to interact socially. Additionally, in the absence of spousal support, mothers belonging to a nonpoor socioeconomic group were more likely to fall under the low stress level category than the mothers from poor households.

\section{Discussion}

Several studies have found that mothers of children diagnosed with ASD had relatively higher adverse health outcomes as compared with fathers. ${ }^{1,17,18}$ This paper draws data of mothers of children diagnosed with ASD who had participated in a cross-sectional study on parental stress and coping in Kerala, India. We administered questions from the PSS ten item scale to participating mothers but found it to be structurally inconsistent in our study sample. Our reduced composite variable for stress had better psychometric value and was used to measure maternal stress levels. The ROC curve analysis suggested this measure to be reasonable as mothers with high anxiety and avoidance behaviors scored significantly higher than others. However, we restricted handling the stress variable as ordinal with three categories. We checked factorial validity of the items on coping as well. While items on religious 
coping were psychometrically very sound, this coping style did not show variation across stress levels. Acceptance, another emotion focused coping style that emerged as a significant dimension, showed association with maternal stress levels.

We found maternal stress to be driven by factors at three levels-characteristics of the child, psychological elements in the mother, and spousal support. A completely dependent child or a child diagnosed with a mixed disorder may cause more distress than children with some degree of independence. Parental stress correlates with the severity of the child's condition. ${ }^{19,20}$ Several parental psychological factors have been shown to be protective. ${ }^{21}$ We found acceptance of the condition to be protective. Other researchers have recommended focus on positive coping mechanisms like acceptance to protect parental psychological health. ${ }^{22}$ Family and social support are important aspects that are known to mitigate stress in mothers of children diagnosed with ASD..$^{23-25}$ However, in communities where gender norms restrict social mobility of women, spousal support becomes extremely important. Our study found low spousal support to be an independent predictor of high stress levels in mothers. In the absence of high spousal support, support from family and friends has been shown to help mothers maintain good physical health functioning. ${ }^{9}$ This may be why mothers with low spousal support but without a problem in social interactions had less stress levels in our study.

It will be useful to explore further the maternal coping strategies that are adaptive, like acceptance, or maladaptive, like avoidant behaviors. Studies have shown that avoidance behaviors are problematic in that they may result in mothers having lesser social activities of values, as well as fewer normative circumstances for the child to be engaged in. ${ }^{26}$ Avoidance coping has also been linked to anxiety in several studies and adaptive coping is thought to offer more benefit than avoidance strategies. ${ }^{27}$ Avoidance has been linked to feelings of despair in mothers of children with a diagnosis of ASD, and interventions for reduction in despair have been shown to be of benefit in terms of burden, stress, and satisfaction in life of such parents. One promising natural and accessible intervention, at least for some mothers, is the creation of peer support groups, preferably ones with involvement of professionals. ${ }^{28}$

We also found that mothers who had difficulty in social interactions had higher stress levels. Avoidance has been found to be adversely related to depression, a feeling of isolation, and problems in marital relationships among parents of autistic children. ${ }^{29}$ In the study on child symptom severity and depressed mood in parents, the buffering effect of social support was stronger when the symptom severity was less. ${ }^{19}$ Our finding is similar, in that the buffering of spousal support was significant when the dependence of the child was partial rather than complete.

\section{Limitations}

Our sample selection was institutional as there is no available registry of autism in Kerala at present. The sample size may have been inadequate to capture interactions, or the measurement may not have permitted enough variance to explore interactions. Also, there is a possibility of selection bias in this study, as we selected mothers recruited who were already part of therapeutic programs and recruited by their immediate care providers. Mothers who would not have reached such institutions due to the delay in diagnosis in the child, or not able to access supportive services may be facing different levels or patterns of stress. However, in Kerala, children with developmental disorders are likely to be diagnosed and treated at reasonably high levels. All institutions with good case load catering for children with disabilities in selected district were included. Thus, the findings are quite likely to be generalizable, at least within the state of Kerala. Also, we did not study the degree of disability of the child, the level of behavioral problems in the child, or the depth of the relationship between the child and the mother, or the actual actions mothers were taking to cope with the stress. These may have important implications on the stress levels of the participating mothers.

\section{Future Research}

Parental self-efficacy, a feeling of parents that they are competent in their parental role, has been found to be a mitigator for high stress levels in parents with low spousal support..$^{30}$ Self-efficacy of mothers with low spousal support can be explored in future studies.

\section{Conclusion}

Caring responsibilities for children diagnosed with ASD often fall disproportionately on mothers. Paternal involvement in bringing up children is embedded in the social and cultural norms of communities and in many low- and middle-income countries like India, fathers have limited role in child-rearing even for neurotypical children. When a family is required to bring up a child diagnosed with ASD, the role of spousal support for care of the child becomes extremely important for the psychological welfare of the corresponding mothers. In situations where spousal support is low or impracticable, emotion-based coping like acceptance may help mothers to mitigate stress levels.

\section{Ethical Approval}

Data collection was initiated after review, and clearance was made by the Institutional Ethics Committee of Sree Chitra Tirunal Institute for Medical Science and Technology, Trivandrum (Reference Number: SCT/IEC/1209/MAY-2018 dated 04 June 2018). Informed consent processes were in line with regulations of the International Conference on Harmonization Good Clinical Practice and tenets of the Declaration of Helsinki.

\section{Authors' Contributions}

P.J. contributed toward the conception and design, acquisition of data, interpretation of data, drafting, and revision of the final article. S.S. contributed toward the recruitment of participants, interpretation of results, and revisions of the final article. R.P.V. performed the conception and design, analysis and interpretation of data, drafting and revision of the final article. 


\section{Funding}

This research was part of the MPH dissertation work of Prinu Jose and did not receive any specific grant from funding agencies in the public, commercial, or not-forprofit sectors.

\section{Conflict of Interest \\ None declared.}

\section{Acknowledgment}

The authors acknowledge the following persons and institutions without whose unwavering support this exercise could not have been possible: S. Harikishore, IAS, Executive Director Kudumbashree; Dr. Babu George, Child Development Centre, Thiruvananthapuram; Dr. Suja K. Kunnath, National Institute of Speech and Hearing, Thiruvananthapuram; Reverend Fr. Thomas Felix CMI, Director, Central Institute for Mental Retardation.

\section{References}

1 Kuhaneck HM, Madonna S, Novak A, Pearson E. Effectiveness of interventions for children with autism spectrum disorder and their parents: a systematic review of family outcomes. Am J Occup Ther 2015;69(5):0040p1-14-, p14

2 Christensen DS, Flensborg-Madsen T, Garde E, Hansen ÅM, Pedersen JM, Mortensen EL. Parental socioeconomic position and midlife allostatic load: a study of potential mediators. BMC Public Health 2018;18(1):1029

3 Fávero-Nunes MA, dos Santos MA. Depression and quality of life in mothers of children with pervasive developmental disorders. Rev Lat Am Enfermagem 2010;18(1):33-40

4 Olsson MB, Hwang CP. Socioeconomic and psychological variables as risk and protective factors for parental well-being in families of children with intellectual disabilities. J Intellect Disabil Res 2008;52(12):1102-1113

5 Diehl M, Hay EL, Chui H. Personal risk and resilience factors in the context of daily stress. Annu Rev Gerontol Geriatr 2012;32(1):251-274

6 Lindström B, Eriksson M. Salutogenesis. J Epidemiol Community Health 2005;59(6):440-442

7 Friedli L, World Health Organization. Mental health, resilience and inequalities. (No. EU/08/5087203) Copenhagen: WHO Regional Office for Europe; 2009. Accessed January 26, 2021 at: https://apps.who.int/iris/bitstream/handle/10665/107925/ E92227.pdf

8 Benson PR, Kersh J. Marital quality and psychological adjustment among mothers of children with ASD: cross-sectional and longitudinal relationships. J Autism Dev Disord 2011;41(12):1675-1685

9 Rini C, Manne S, DuHamel K, et al. Social support from family and friends as a buffer of low spousal support among mothers of critically ill children: a multilevel modeling approach. Health Psychol 2008;27(5):593-603

10 Bristol MM, Gallagher JJ, Schopler E. Mothers and fathers of young developmentally disabled and nondisabled boys: adaptation and spousal support. Dev Psychol 1988;24:441-451

11 Thresia CU, Mohindra KS. Gender bias in health research: implications for women's health in Kerala (India) and Sri Lanka. Crit Public Health 2011;21:327-337

12 Sarrett JC. Custodial homes, therapeutic homes, and parental acceptance: parental experiences of autism in Kerala, India and Atlanta, GA USA. Cult Med Psychiatry 2015;39(2):254-276

13 Cohen S, Kamarck T, Mermelstein R. A global measure of perceived stress. J Health Soc Behav 1983;24(4):385-396
14 CarverCS,Scheier MF, WeintraubJK.Assessing coping strategies: a theoretically based approach. J Pers Soc Psychol 1989;56(2): 267-283

15 Indian Council of Medical Research. National ethical guidelines for biomedical and health research involving human participants. New Delhi: Indian Council of Medical Research; 2017. Accessed January 26, 2021 at: https://ethics.ncdirindia.org// asset/pdf/ICMR_National_Ethical_Guidelines.pdf

16 Office of the Drugs Controller General (India). Re-registration of Ethics Committees. 2017. New Delhi: Central Drugs Standard Control Organization. Accessed January 26, 2021 at: https://cdsco.gov.in/opencms/opencms/system/ modules/CDSCO.WEB/elements/download_file_division. jsp?num_id=MjY3Mg==

17 Jones L, Totsika V, Hastings RP, Petalas MA. Gender differences when parenting children with autism spectrum disorders: a multilevel modeling approach. J Autism Dev Disord 2013;43(9):2090-2098

18 Masefield SC, Prady SL, Sheldon TA, Small N, Jarvis S, Pickett KE. The caregiver health effects of caring for young children with developmental disabilities: a meta-analysis. Matern Child Health J 2020;24(5):561-574

19 Benson PR. The impact of child symptom severity on depressed mood among parents of children with ASD: the mediating role of stress proliferation. J Autism Dev Disord 2006;36(5):685-695

20 Soltanifar A, Akbarzadeh F, Moharreri F, et al. Comparison of parental stress among mothers and fathers of children with autistic spectrum disorder in Iran. Iran J Nurs Midwifery Res 2015;20(1):93-98

21 Benson PR. The longitudinal effects of network characteristics on the mental health of mothers of children with ASD: the mediating role of parent cognitions. J Autism Dev Disord 2016;46(5):1699-1715

22 Weiss JA, Cappadocia MC, MacMullin JA, Viecili M, Lunsky Y. The impact of child problem behaviors of children with ASD on parent mental health: the mediating role of acceptance and empowerment. Autism 2012;16(3):261-274

23 Bromley J, Hare DJ, Davison K, Emerson E. Mothers supporting children with autistic spectrum disorders: social support, mental health status and satisfaction with services. Autism 2004;8(4):409-423

24 Montes G, Halterman JS. Psychological functioning and coping among mothers of children with autism: a population-based study. Pediatrics 2007;119(5):e1040-e1046

$25 \mathrm{Sim}$ A, Vaz S, Cordier R, et al. Factors associated with stress in families of children with autism spectrum disorder. Dev Neurorehabil 2018;21(3):155-165

26 Lucyshyn JM, Irvin LK, Blumberg ER, Laverty R, Horner RH, Sprague JR. Validating the construct of coercion in family routines: expanding the unit of analysis in behavioral assessment with families of children with developmental disabilities. Res Pract Persons Severe Disabl 2004;29(2):104-121

27 Pattini E, Carnevali L, Troisi A, et al. Psychological characteristics and physiological reactivity to acute stress in mothers of children with autism spectrum disorder. Stress Health 2019;35(4):421-431

28 Da Paz NS, Siegel B, Coccia MA, Epel ES. Acceptance or despair? Maternal adjustment to having a child diagnosed with autism. J Autism Dev Disord 2018;48(6):1971-1981

29 Dunn ME, Burbine T, Bowers CA, Tantleff-Dunn S. Moderators of stress in parents of children with autism. Community Ment Health J 2001;37(1):39-52

30 Lavenda O, Kestler-Peleg M. Parental self-efficacy mitigates the association between low spousal support and stress. Psychiatry Res 2017;256:228-230 